sig web

\title{
The Narrative and Hypertext Workshop Series and the value of Workshops to Research Communities
}

\author{
Charlie Hargood \\ Bournemouth University, UK
}

Narrative and Hypertext (NHT) is the longest running workshop series at ACM Hypertext, and as it enters its 8th year we reflect on the value of workshops to research communities, and how they enable dissemination and discussion in a different, but equally valuable, form to conferences. We look at NHT as a case study, and how through providing a publication venue for new ideas and early work alongside a substantial platform for key discussions it has supported it's community.

\section{INTRODUCTION}

Conferences and Workshops commonly run alongside each other and serve a similar, but subtly different, role in research publication and events. In this short article I will review the value of these events and unpack some of my own thoughts on this matter as the organizer of a long running workshop series, using my own workshop Narrative and Hypertext (NHT) as a case study to frame the discussion.

\section{THE VALUE OF CONFERENCES AND WORKSHOPS}

Conferences serve two important purposes in research: dissemination and discussion. The value in dissemination comes from publication and presentation - a conference allows us to share our own research contributions, and understand the research contributions of others along with contemporary issues of our field through research papers and presentations. This is a corner stone of academic research, but it is not the only value of conferences - a researcher might get much of the value of that through simply reading papers, as seen in academic journals. However what remote participation and journals can't provide is the dialog - the conversation and discourse that makes up the community that is a research field. This comes from the questions, the conversations over breaks and evenings, and ad hoc meetings organized throughout conferences - and this is arguably just as valuable as the dissemination itself. Face to face discussions between research leaders in a free environment such as a conference is what might stimulate new ideas for directions of work within the field, fosters collaboration, and allows those research leaders to plan and coordinate in a way that might take several months remotely or not happen at all. Outside of a conference this discourse may be limited to much more local cliques, or restricted to a more narrow focus on particular projects rather than the wider issues facing a field. 
Workshops serve a similar purpose: dissemination and discussion. However they serve a different role in supporting each of these. Whereas conferences serve the dissemination of mature work with a solid research contribution, workshops support early and student work. While the academic impact of this might be less it is equally important both in the sense of training future researchers by providing a host for student work, and providing a venue for exciting new ideas unconstrained by the demands of a full research paper. Because the value determining a workshop paper publication is normally its ability to stimulate and inform useful discussion for the community rather than the strength of its research contribution they solicit a rather different genre of work. New ideas and innovations are the lifeblood of research but often benefit from early discussion and critique despite not being mature enough to warrant a full publication. This need for the publication of ideas as well as results is what has also stimulated the recent resurgence of "Blue Skies" tracks in computer science conferences - and the papers there often bear a striking similarity to some workshop papers (though are perhaps more ambitious in scale and scope). Without workshops we would lose a substantial part of this vital contribution to scholarly discourse.

Similarly workshops serve research discussion differently to conferences, in that while a conference brings research leaders together and provides numerous short conversations the flexible structure of a workshops enables longer and more strategic conversations in contrast to the more tactical issue focused ones after a particular presentation in a conference. This more informal talking shop less restricted in time and scope is not dissimilar to the intellectual "Salons" of the renaissance, and arguably workshops serve a similar role to this in the modern day as a sounding board for new ideas and an opportunity to learn from peers. Panel sessions, unconferences, and plenary discussions, are all more commonly within the domain of workshops than conferences (although the author accepts this observation is anecdotal, and not by necessity) and allow for a substantial discourse inspired by the ideas of its publications to direct a particular field or the future challenges of a particular area. Dedicating an hour to public discussion of an issue is difficult to schedule in a conference but easy to achieve within a workshop. The network of a workshop can also be more specialised in that it doesn't demand the breadth that comes with the scale of a full conference - allowing for a home for smaller more specialized communities, or nascent fields still emerging into their own that are not yet ready for a conference. Furthermore as workshops provide a publication entry point for student work, they also serve as an entry point for younger researchers into their related research communities, and alongside doctoral consortiums can be responsible for providing fresh blood to any conference. This contribution is again, undoubtedly valuable, both in a home for smaller communities and a venue for broader debate and discussion, that would be lost without workshops.

\section{NHT: A CASE STUDY}

$\mathrm{NHT}^{1}$ is the longest running workshop series at ACM Hypertext, this year running for the 7th time (and longer if you include arguably similar previous workshops not under the same name such as the Hyperstructure workshop in Salzburg 2005). It started in 2011 and has run alongside ACM Hypertext every year since then with the single exception of 2014. Narrative systems has a long history of work within Hypertext and the first ever Douglas

\footnotetext{
${ }^{1}$ http://nht.ecs.soton.ac.uk

SIGWEB Newsletter Summer 2018
} 


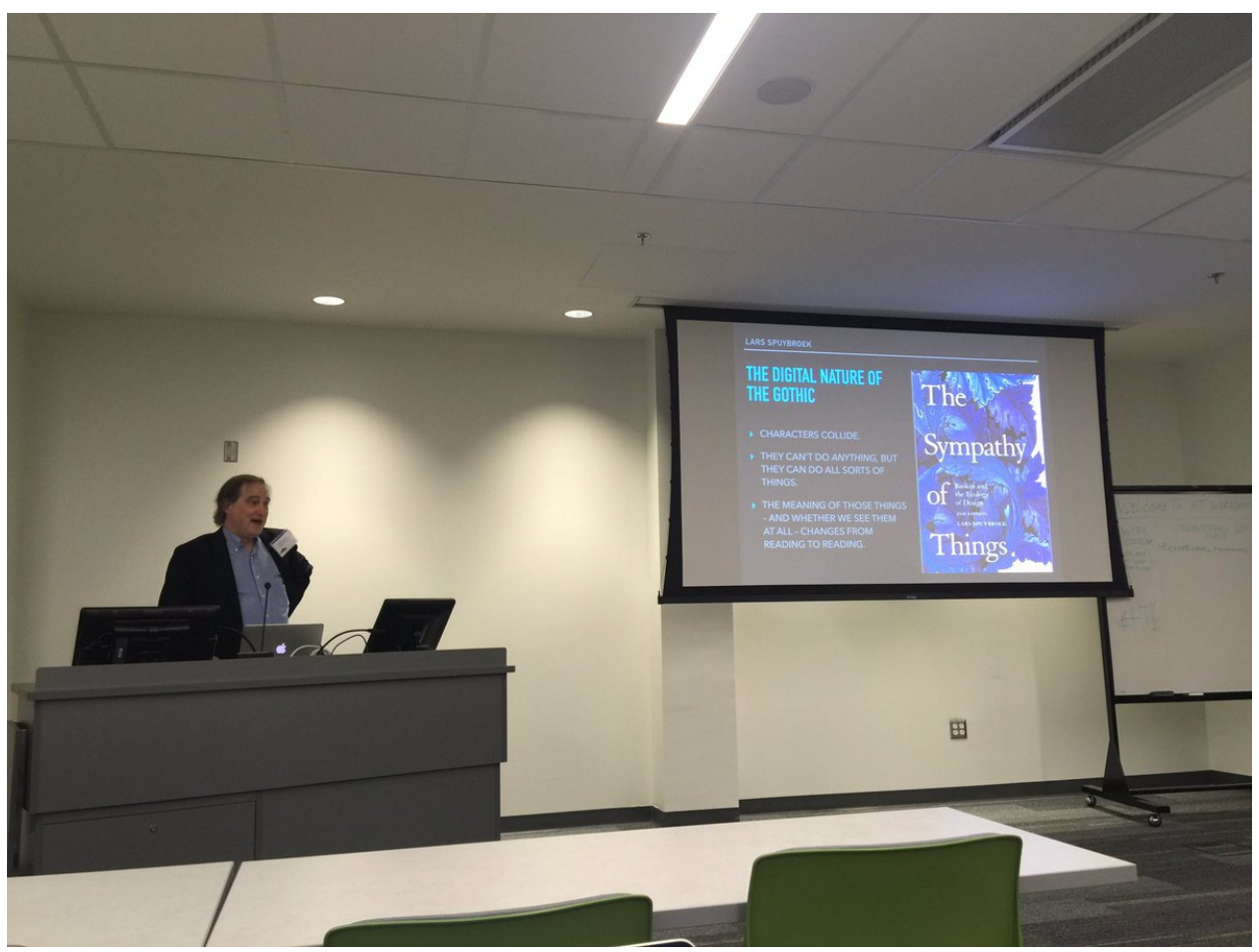

Fig. 1. Mark Bernstein talking at NHT '16, Halifax

Englebart best paper award at Hypertext was awarded to a narrative hypertext work in 1996 (the sublime HyperCafe [Sawhney et al. 1996]). While its proportion of the community is smaller now that makes it ideal for the subject matter of a workshop and while Narrative Hypertext papers continue to make it into the main conference proceedings every year NHT has provided a home for more focused and in-depth discussions in this space for this community. NHT's mission statement is to provide an interdisciplinary forum for digital writers and humanists and computer scientists to come together and explore new hypertext narrative research and current challenges facing the field. In this sense NHT serves as the valuable home for a smaller community as discussed above.

Structurally NHT seeks to strike a balance between the noted goals of dissemination and discourse. Each year we have attempted to divide the time roughly equally between traditional presentation sessions, and more open discussion sessions. This way our paper presentations achieve the first purpose above of providing an entry point for students, and a venue for the appraisal of earlier ideas and innovations, and the discussion session achieve the second purpose of enabling broader conversations to bring the community together and tackle greater issues in more depth. We have approached these discussion sessions in a variety of ways previously including panels and plenary debates but a regular feature of the workshop has become an unconference ${ }^{2}$ session. The agenda of this session is normally

\footnotetext{
${ }^{2}$ Unconference: a loosely structured participant driven meeting where by the agenda is defined at the time of meeting by those in attendance
} 
crowd sourced throughout the day (topics often being collected on a white board) allowing for agenda items to be added as they arise either through inspiration from a point raised in a paper presentation or at the behest of an attendee who has come wishing to discuss a particular topic. Organizers then survey interest in these topics from those in attendance and host either plenary discussions or breakout meetings on particular sub topics. This gives the workshop tremendous agility in terms of satisfying the broader discussions required by the community and matching the interests of those actually present rather than just the agenda of the organizers.

The workshop series has had numerous tangible outcomes in its seven years beyond its papers and providing a home for its community. It has formed the basis of a number of collaborations from its group which has in turn led to subsequent projects (such as the fractal hypertext work [Hargood et al. 2012]). Future gazing discussions on the future of the field in 2012 at the workshop were also behind new momentum in the area of locative hypertext, which subsequently inspired work which has since twice won the Douglas Englebart award at ACM Hypertext [Millard et al. 2013; Hargood et al. 2016]. Furthermore every few years the workshop as part of its discussions appraises the "Grand Challenges" of the Narrative and Hypertext field in order to form community consensus on what the big problems are in the space. In 2013 these were agreed as:

(1) Effective machine readable model of narrative

(2) Authoring tools

(3) Procedural narrative generation

Where as in 2017 the consensus was:

(1) Methodologies for evaluating digital narrative and related technology

(2) Authoring tools

(3) Further interdisciplinary engagement with the creative community

It is a valuable exercise to reflect and consider what the broader problems area in a given community to avoid becoming too concerned with only what is immediately in front of us, to take a step back and look at the field as a whole. However this exercise also provides an enlightening window on to how the attitudes and priorities of the community is changing. Narrative and Hypertext is now less concerned with singular unifying models and procedural generation, and more so with authors and the author and reader experience. Authoring tools, and how to enable the creation of narrative hypertext, has remained the "million dollar question" throughout this time, and the importance of this issue is reflected in attention in other digital narrative research communities such as interactive fiction and game narrative.

As it enters its 8th year NHT is looking to expand further, something that has become increasingly clear from the workshop is that the narrative systems research community is fragmented across a wide variety of overlapping research communities of which narrative and hypertext is only one part. As I have repeatedly stated in this article, one of the values of workshops is the way they enable dialogue and towards that and building connections between the varied parts of the narrative systems research community we have begun a 


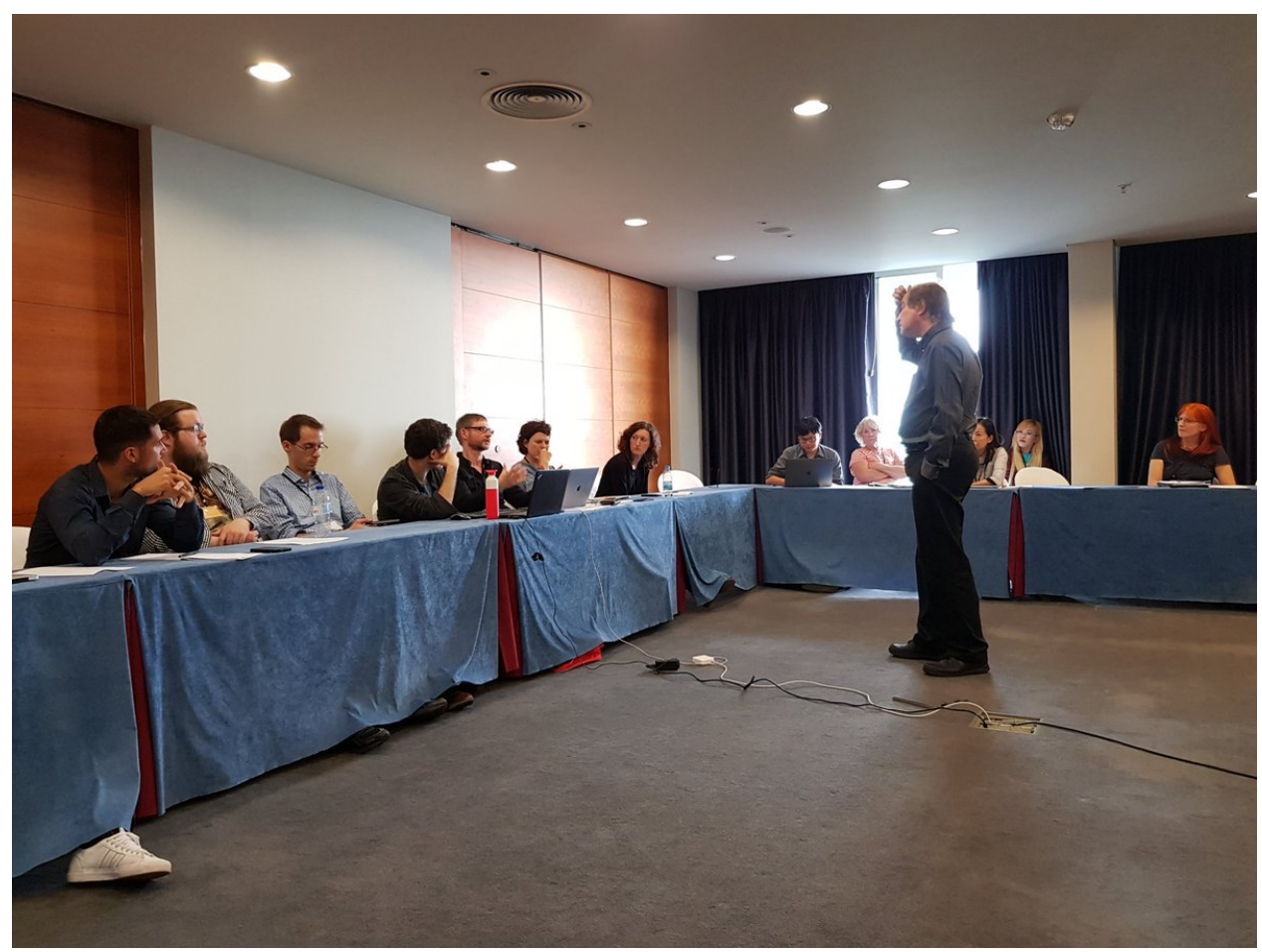

Fig. 2. NHT's "sister" workshop - AIS'17, Madiera

new "sister" workshop series to NHT hosted at the interactive fiction conference ICIDS. This workshop will focus on that most enduring of problems to the community - authoring tools - and is titled Authoring for Interactive Storytelling (AIS) ${ }^{3}$. We hope this will encourage a degree of "cross pollination" between different groups in narrative systems research. Longer term we hope to build a network of related workshops that can host this community, provides for dissemination and networking, and enables cross collaboration and communication between its different facets.

\section{CONCLUSIONS}

Conferences and Workshops both seek to enable dissemination and networking for their research communities, however they both aid in this in different and equally important ways. Workshops provide an essential entry point for young researchers joining the field, a venue for encouraging and appraising new ideas and innovations without the limitations of a full research publication, and a platform for larger discussions than what is normally possible within a conference. They serve a crucial role in our communities which demands support.

Narrative and Hypertext (NHT) is an example of what is possible with continued support for a workshop - a well-supported community, with tangible outputs, a continually evolving

\footnotetext{
${ }^{3}$ http://narrativeandplay.org/ais/
} 
discussion, and a platform for dissemination and networking that exists in close symbiosis with its host conference. NHT now progresses into its 8th year and seeks to expand through associated workshops and to avoid stagnation by directly addressing the issues defined by its own participants.

\section{ACKNOWLEDGMENTS}

I would like to acknowledge my co-organizer of NHT, David Millard (whose photographs are also used in this article), the long serving NHT Programme Committee without which the workshop would not be possible, and our collaborators in the newly formed AIS workshop Alex Mitchell and Ulrike Spierling.

\section{REFERENCES}

Hargood, C., Davies, R., Millard, D. E., Taylor, M. R., and Brooker, S. 2012. Exploring (the poetics of) strange (and fractal) hypertexts. In Proceedings of the $23 \mathrm{rd}$ ACM conference on Hypertext and social media. ACM, 181-186.

Hargood, C., Hunt, V., Weal, M. J., And Millard, D. E. 2016. Patterns of sculptural hypertext in location based narratives. In Proceedings of the 27th ACM Conference on Hypertext and Social Media. ACM, 61-70.

Hargood, C., Weal, M., And Millard, D. 2018. The storyplaces platform: Building a web-based locative hypertext system. In Proceedings of the 29th ACM Conference on Hypertext and Social Media.

Millard, D. E., Hargood, C., Jewell, M. O., And Weal, M. J. 2013. Canyons, deltas and plains: towards a unified sculptural model of location-based hypertext. In Proceedings of the 24th ACM Conference on Hypertext and Social Media. ACM, 109-118.

SAWhney, N., BALCOM, D., AND SMith, I. 1996. Hypercafe: narrative and aesthetic properties of hypervideo. In Proceedings of the the seventh ACM conference on Hypertext. ACM, 1-10.

Charlie Hargood is a senior lecture at Bournemouth University in the department of creative technology, and is best known for his work on narrative systems, most recently in the form of locative hypertext and the StoryPlaces project ${ }^{4}$. He is organiser for both the NHT and AIS workshops, and Information Director for ACM SIGWeb. His latest publication is entitled "The Storyplaces platform: Building a web-based locative hypertext system" [Hargood et al. 2018] and was published in the 29th ACM International Conference of Hypertext and Social Media.

\footnotetext{
${ }^{4} \mathrm{http}: / /$ storyplaces.soton.ac.uk/
} 